\title{
A FORMAÇÃO CONTINUADA NO LOCAL DE TRABALHO DO \\ PROFESSOR E A CONSTRUÇÃO DE UMA COMUNIDADE DE PRÁTICA: POSSIBILIDADE DE AGÊNCIA SOCIAL
}

\section{Paula Baracat De Grande}

Universidade Estadual de Campinas

\begin{abstract}
Resumo
Neste artigo, analiso um recorte de um corpus gerado para uma pesquisa de doutorado em andamento que tem por objetivo investigar formação continuada do professor em seu local de trabalho. Trata-se de uma pesquisa qualitativa-interpretativista e de cunho etnográfico que tem como corpus dados gerados em observação participante em reuniões de Hora de Trabalho Pedagógico Coletivo de Ensino Fundamental I em uma escola do interior paulista. Inserido no campo transdisciplinar da Linguística Aplicada, o estudo baseia-se na perspectiva sociocultural dos Estudos de Letramento e na concepção dialógica de linguagem do Círculo de Bakhtin. Neste trabalho, trago a análise de um comunicado oficial que regula a prática de HTPC e de dados de interação gerados nessas reuniões com o intuito de mostrar que, apesar das restrições institucionais, quando conseguem construir uma comunidade de prática, um coletivo para se identificar, as professoras organizam suaprópria formação, constroem a possibilidade de agência social nesse contexto e direcionam suas aprendizagens conforme suas próprias demandas profissionais.
\end{abstract}

Palavras-chave: letramento; formação do professor no local de trabalho; agência social.

\footnotetext{
* Doutoranda em Linguística Aplicada no Instituto de Estudos da Linguagem (UNICAMP), pesquisadora do Grupo Letramento do Professor.

Olh@res, Guarulhos, v. 2, n. 2, p. 60-85. Dezembro, 2014.
} 


\title{
Continuing education in the teacher's workplace and the construction of a community of practice: possibilities for social agency
}

\begin{abstract}
:
This paper examines a segment of a thesis that has as its research object the teachers continuing education in their workplace. The methodological framework is qualitative and interpretive and based on ethnographic descriptions. The research corpus is composed of data generated in participated observation in official teachers' meetings in an Elementary School in São Paulo State. The work follows a transdisciplinary approach characteristic of Applied Linguistic studies and is supported theoretically by the New Literacy Studies and the Bakhtin Circle approach to discourse studies. The paper brings an analysis which shows that, when teachers can build a community of practice, a collective to get identify with, they organize their own continuing education, they build social agency in this context and they direct their learning according to their own professional demands.
\end{abstract}

Keywords: literacy studies; teachers continuing education in their workplace; social agency. 
Paula Baracat De Grande

\section{Introdução}

A formação do professor costuma ser investigada em cursos acadêmicos de formação inicial e continuada, em instituições públicas e particulares de ensino superior, ou em cursos oportunizados por gestores públicos em parcerias com as universidades. Outro espaço de formação do professor pouco investigado é o próprio local de trabalho do professor. Há uma formação que se dá no cotidiano escolar, a qual fica, muitas vezes, fora dos interesses das agências de pesquisa ou de formação em serviço (SANTOS; ORGE, 2010), e em que ocorrem diversos eventos de letramento que interferem na formação do professor.

Em geral, saberes disciplinares (relacionados aos saberes científicos) e curriculares (baseados nos programas escolares ou de Estado) (TARDIF, 2003) são considerados a base da formação profissional do professor aos quais se tem acesso nas disciplinas teóricas em cursos de formação inicial e continuada ou em disciplinas de estágios nas universidades e faculdades. Em outros espaços, como em reuniões de corpo docente na escola, a discussão entre pares sobre o fazer em sala de aula, o compartilhamento de experiências pedagógicas, de atividades didáticas e exemplificações de possíveis trabalhos pedagógicos configuram-se como momentos formativos para os participantes em que esses e outros saberes, como os experienciais (TARDIF, 2000, 2003) são mobilizados.

O que é considerado como formação depende da situação comunicativa. Entender formação dessa maneira envolve levar em conta, em primeiro lugar, as vozes dos participantes e como estes constroem os eventos como formativos, ou seja, suas apreciações valorativas (BAKHTIN/ VOLOCHINOV, ([1929]/1995) sobre os objetos do discurso e sobre seus interlocutores. Trazer a voz do outro para a pesquisa está em consonância com a perspectiva metodológica qualitativa e etnográfica. Mais do que isso, essa é também uma postura ética na relação com as Olh@res, Guarulhos, v. 2, n. 2, p.60-85. Dezembro, 2014. 
A formação continuada no local de trabalho do professor e a construção de uma comunidade de prática: possibilidades de agência social

participantes da pesquisa de doutorado ${ }^{2}$ em que se baseia este artigo: professoras alfabetizadoras que frequentemente tem suas vozes sobre seu próprio fazer silenciadas e suas visões invisibilizadas nas discussões sobre educação (KLEIMAN, 2013).

Na perspectiva transdisciplinar e crítica da Linguística Aplicada, em busca de resultados que possibilitem impacto na realidade social para transformá-la (FABRÍCIO, 2006), a investigação de práticas de letramento do professor em sua formação no local de trabalho visa a alcançar compreensões sobre estas e sobre demandas profissionais docentes que possam (re)orientar cursos de formação, principalmente na modalidade continuada.

Neste artigo, analiso um recorte de dados de minha pesquisa de doutorado, que busca identificar, compreender e analisar práticas de letramento de formação docente no local de trabalho do professor, mais especificamente, em reuniões do corpo docente que, no Estado de São Paulo, eram chamadas, de acordo com a Portaria da Coordenadoria de Estudos e Normas Pedagógicas (doravante CENP)n. 1/96, de Hora de Trabalho Pedagógico Coletivo (doravante HTPC) ${ }^{3}$. O enfoque dado neste texto é a construção de um coletivo entre professoras, com o qualelas se identificam, mesmo provisoriamente, e em que se sustentam para atuar em sua própria formação profissional.

A pesquisa tem como corpus dados gerados por observação participante, acompanhada de gravação em áudio, coleta documental e diário de campo, em reuniões de HTPC de dois tipos: i) reunião semanal em uma escola de Ensino Fundamental I, relacionada ao cotidiano da unidade escolar, planejada e realizada pela coordenadora da escola, com professoras de $1^{\circ}$ a $5^{\circ}$ ano como participantes (formato mais comum de

\footnotetext{
${ }^{2}$ Pesquisa de doutorado em andamento sob orientação da Profa. Dra. Angela Kleiman no Programa de Pósgraduação em Linguística Aplicada do Instituto de Estudos da Linguagem (UNICAMP).

${ }_{3}$ A partir de 2012, modificou-se o nome para Aula de Trabalho Pedagógico Coletivo (ATPC) devido à alteração de duração: de 60 para 50 minutos, igualando ao tempo de hora-aula sobre o qual o professor recebe seu salário. Opto por manter a nomenclatura anterior, pois nos dados gerados para a pesquisa, tanto nos documentos quanto nas falas das participantes, o nome utilizado era HTPC.

Olh@res, Guarulhos, v. 2, n. 2, p.60-85. Dezembro, 2014.
} 
Paula Baracat De Grande

HTPC); ii) reunião quinzenal, inicialmente organizada pela Secretaria Municipal de Educação com foco nas grandes avaliações sistêmicase destinada a professoras de $5^{\circ}$ ano de toda a rede. Neste artigo, os dados interacionais analisados são do segundo tipo de reunião.

Estudos de Letramento e a concepção dialógica de linguagem na análise da formação do professor em seu local de trabalho

Muitas vezes, a avaliação do que faz o professor da escola básica é realizada tendo em vista parâmetros acadêmicos, principalmente os relacionados à escrita. Esta, como mostram pesquisas do grupo Letramento do Professor, pode se tornar um poderoso mecanismo de constituição da subalternidade dos docentes (KLEIMAN, 2006, 2013; KLEIMAN, VIANNA, DE GRANDE, no prelo), como também pode ser usada para subverter essa subalternidade. Como grupo de pesquisa, buscamos perspectivas que permitam ouvir as vozes de um grupo, professoras alfabetizadoras, cujos saberes não são legitimados por aqueles que têm vozes poderosas socialmente, como a academia, a grande imprensa e o Estado, e considerá-las como produtoras de conhecimentos que podem ser legitimados e integrados em formações oferecidas por instituições de prestígio.

Como destaca Matencio (2009, p. 6), “a contribuição determinante de estudos sobre o letramento resulta de assumirem que se lida, sempre, com práticas - no plural" e que essa perspectiva procura "flagrar e compreender as atividades de leitura e escrita no âmbito das práticas sociais em que ocorrem" (MATENCIO, 2009, p.5), o que permite a investigação dos usos efetivos da linguagem, em diferentes grupos e por diferentes sujeitos. Em outras palavras, permite ouvir as vozes de grupos sociais como das professoras da escola básica. Tal compreensão dos usos da língua como sempre situados coaduna-se com a compreensão de que a linguagem nunca se dá no vazio, mas sempre numa situação histórica e Olh@res, Guarulhos, v. 2, n. 2, p.60-85. Dezembro, 2014. 
A formação continuada no local de trabalho do professor e a construção de uma comunidade de prática: possibilidades de agência social

social concreta, através da interação (VOLOCHINOV/ BAKHTIN, 1995).

A perspectiva dos Estudos de Letramento, que compreende o letramento como um conjunto de práticas discursivas que envolve os usos da escrita (KLEIMAN, 1995), ajuda a entender as práticas relacionadas à formação do professor de maneira situada, sem desconsiderar as intersecções com contextos sócio-históricos mais amplos. Isso porque essa perspectiva, numa abordagem etnográfica de pesquisa, busca investigar as práticas sociais de uso da língua e os significados que os participantes a elas atribuem sem perder de vista as relações de poder, as dinâmicas identitárias e as diferentes forças que atuam nos contextos investigados. Investigar práticas de letramento envolve investigar os valores, as significações, os conhecimentos mobilizados pelos participantes (KLEIMAN, 1995), elementos constitutivos das práticas e que indicam aspectos sócio-históricos destas, inclusive seus diálogos harmoniosos e conflituosos com diferentes vozes sociais (BAKHTIN, 1988), mais ou menos poderosas, com mais ou menos penetração em instâncias políticas e educacionais no que se refere à formação do professor.

A noção de práticas de letramento, entendidas como formas culturais de utilização da língua escrita, que envolvem "aspectos não apenas da cultura, mas também das estruturas de poder numa sociedade" (KLEIMAN, 1995, p. 38), permite refletir sobre a relação entre as atividades que envolvam o uso da escrita na formação de professores e as estruturas sociais em que elas estão inseridas. Assim, estudar as práticas de letramento formativas no local de trabalho do professor envolve não só investigar o que se lê e escreve, mas que valores estão em disputa ao se ler, escrever e falar sobre o que se lê e escreve, que significações são construídas naquela situação específica pelo grupo de professoras ao participar dessas práticas.

O destaque de pesquisas que se voltam para letramento(s) é o

Olh@res, Guarulhos, v. 2, n. 2, p. 60-85. Dezembro, 2014. 
olhar situado para as práticas sociais de uso da escrita em determinada esfera. Nesse sentido, a teorização bakhtiniana é bastante fértil, pois coloca em jogo conceitos como arena de combate, palavras e contrapalavras e forças centrífugas e centrípetas que sempre agem nas diversas esferas de atividade humana (BAKHTIN, 2003), e entende o diálogo também como conflito que pode servir a subversões de padrões por grupos minoritários.

Considerando, portanto, o(s) letramento(s) como práticas sociais situadas de uso da escrita, que envolvem negociações entre os participantes, a análise da interação entre professoras, coordenadora e outros agentes da formação em HTPC ganha importância. Pesquisas do grupo Letramento do Professor mostram que é na interação que se constroem identidades e papéis sociais, ressignificando as práticas de letramento e reconfigurando o espaço discursivo de sala de aula (KLEIMAN, 1998, 2005, SILVA, MATENCIO, 2005, SANTOS, 2005). Nesse sentido, busco compreender as dinâmicas discursivas e interacionais em outro espaço de formação, o local de trabalho do professor, também pelo fato de ser um espaço em que se constroem papéis sociais e identidades profissionais para os agentes envolvidos: professoras, coordenadoras, diretoras de escolas, funcionários da secretaria de educação e outros agentes, como a própria pesquisadora, consultores pedagógicos e representantes de editoras de materiais didáticos.

Nessa perspectiva, os dados e análises buscam abordar o "letramento do professor" (KLEIMAN, 2001), que se refere às práticas que envolvem os usos da escrita relacionados à atuação e à formação profissional do professor, dando destaque à agência das professoras participantes em sua própria formação. Tais conceitos ajudam a compreender a formação do professor no local de trabalho, pois levam o olhar para o que é específico das práticas de letramento do professor, para os sentidos situadamente construídos.

Olh@res, Guarulhos, v. 2, n. 2, p. 60-85. Dezembro, 2014. 
A formação continuada no local de trabalho do professor e a construção de uma comunidade de prática: possibilidades de agência social

Ao compreender a linguagem como dialógica, a realidade da língua se configura como uma cadeia verbal, sendo que cada elo dessa cadeia é social, assim como toda a dinâmica de sua evolução. Com base na perspectiva do Círculo, a verdadeira substância da língua é constituída pelo fenômeno social da interação verbal, sendo que o diálogo, no sentido estrito do termo, é apenas uma das formas de interação, já que “pode-se compreender a palavra 'diálogo' num sentido amplo, isto é, não apenas como a comunicação face a face, mas toda comunicação verbal, de qualquer tipo que seja" (BAKHTIN/VOLOCHINOV, 1995, p. 123). Dessa forma, a análise não se restringe às interações entre os agentes presentes na formação do professor em seu local de trabalho, incluindo os diálogos entre vozes sociais que emergem nesse contexto.

A dialogicidadeconstitutiva de todo enunciado e os sentidos sóciohistóricos em embate se refletem e refratam na própria palavra. Encarada como parte do processo de interação, a palavra acumula entoações do diálogo vivo dos interlocutores com valores sociais e é o indicador mais sensível de toda transformação social; "as palavras são tecidas a partir de uma multidão de fios ideológicos e servem de trama a todas as relações sociais em todos os domínios" (BAKHTIN/VOLOCHINOV, 1995, p. 41). A palavra aponta para uma realidade externa a ela, mas sempre de modo refratado, sempre construindo diversas interpretações desse mundo, através de diferentes apreciações valorativas, inerentes aos enunciados. No uso da palavra, sempre nos posicionamos axiologicamente e adentramos uma corrente ininterrupta de interações.

\section{A HTPC, regulamentação oficial e as possibilidades de formação docente}

As práticas de formação de professores situadas na escola são constituídas na interação de diferentes agentes, principalmente professoras e coordenadora, sujeitos diretamente envolvidos nos eventos 
observados. Essa formação ocorre nas reuniões semanais de HTPC ou em iniciativas da Secretaria Municipal de Educação, como a realização de palestras, workshops ou reuniões de HTPC com professores de toda a rede que lecionam num mesmo ano do Ensino Fundamental.

A existência de um momento remunerado para se discutir os problemas da escola e da Educação esteve na pauta das reivindicações dos professores do Estado de São Paulo durante décadas. Como destaca Oliveira (2006, p. 28) “essas reivindicações começaram a ter resultados quando os governos começaram a reconhecer que o trabalho do professor vai além de sua presença em sala de aula, ao instituírem a HTP (hora de trabalho pedagógico) no Estatuto do Magistério em 1985". Posteriormente, no interior do Projeto Ciclo Básico, foi criada a HTPC, destacando o caráter coletivo desse trabalho.

Souza (1996) aborda a situação do professor e da escola pública estadual paulista na década de 80 e início dos anos 90, e afirma que o professor era compreendido como um trabalhador do espaço de sala de aula, e pouca relevância era dada a espaços coletivos de discussão e formulação de propostas educacionais: o professor era tido como um “aulista" (SOUZA, 1996, p. 111). Ao analisar depoimentos relativos à qualificação profissional, a autora destaca a relevância dada pelos professores para o coletivo: “[os professores] são explícitos em afirmar que foi no espaço coletivo do trabalho, com colegas e os alunos, que encontraram a possibilidade do fazer. Ou seja, superaram, no nível do coletivo, as dificuldades que se apresentavam como individuais" (SOUZA, 1996, p. 66).

Segundo a Portaria da CENP no $1 / 96$ - L.C. $n^{\circ} 836 / 97$, as reuniões de HTPC são atribuídas como parte da jornada do titular de cargo, e como carga horária para o OFA (Ocupante de função atividade), desde que esses professores tenham, no mínimo, dez aulas atribuídas. As horas destinadas à HTPC também podem ser utilizadas em atividades pedagógicas e de estudo, de caráter coletivo, bem como no atendimento a Olh@res, Guarulhos, v. 2, n. 2, p. 60-85. Dezembro, 2014. 
A formação continuada no local de trabalho do professor e a construção de uma comunidade de prática: possibilidades de agência social

pais de alunos, o que demonstra que suas possíveis funções são bastante variadas.

A HTPC é um espaço destinado, em tese, para discussão e implementação do projeto pedagógico da escola, para discussão de problemas enfrentados pela unidade escolar e suas possíveis soluções, além de ser um espaço de reflexão docente sobre sua prática, ou seja, envolveria eventos de formação do professor.

Como evento de letramento, a HTPC pode ser mais ou menos ritualizada. Eventos configuram-se com base em rotinas comunicativas, já que a interação entre os participantes tem um código ritual (GOFFMAN, [1974] 2011), mas há eventos “cujas rotinas comunicativas que constituem suas unidades funcionais são mais rígidas do que as encontradas em outros" (MATENCIO, 1999, p. 65). Os fatores que influenciam na maior ou menor espontaneidade na organização comunicativa de um evento são tanto relacionados ao estatuto dos interlocutores e às relações entre eles estabelecidas quanto a determinações institucionais, relacionadas ao espaço-tempo em que os eventos ocorrem.

No caso da HTPC, alguns fatores são pré-determinados: horário de início e fim, duração do evento, interlocutores autorizados a participar e seus papéis ou funções (professoras, coordenadora e, esporadicamente, diretora). A própria portaria que regulamenta a HTPC restringe as características do evento. Por exemplo, complementando a Portaria $n^{\circ}$ 1/96 - L.C. $n^{\circ}$ 836/97, a CENP esclarece e reitera objetivos e formas de organização da HTPC em comunicados que delimitam duração, participantes e suas funções nos eventos assim como modos de agir (elaborar pauta, dividir tarefas etc.), artefatos a serem usados (ata, caderno, diário de bordo) gêneros a serem mobilizados pelos participantes (debate, oficina, reunião, pauta, ata), como indicam os trechos a seguir:

\section{Quadro 1: Comunicados CENP sobre HTPC}

Olh@res, Guarulhos, v. 2, n. 2, p. 60-85. Dezembro, 2014. 
"Comunicado CENP de 29/01/2008

(...) 1 - As Horas de Trabalho Pedagógico Coletivo deverão ser planejadas e organizadas pelo Professor Coordenador de cada segmento do ensino fundamental e médio, em sintonia com toda a equipe gestora da escola, com vistas a integrar o conjunto de professores do segmento, objeto da coordenação; (...)".

"Comunicado CENP, de 06/02/2009

(...) 4 - No planejamento, na organização e na condução das HTPCs, é importante: - considerar as demandas dos professores frente às metas e prioridades da escola; - elaborar previamente a pauta de cada reunião, definida a partir das contribuições dos participantes;

- dividir entre os participantes as tarefas inerentes às reuniões (registro, escolha de textos, organização dos estudos);

- planejar formas de avaliação das reuniões pelo coletivo dos participantes;

- prever formas de registro (ata, caderno, diário de bordo, e outras) das discussões, avanços, dificuldades detectadas, ações e intervenções propostas e decisões tomadas;

- organizar as ações de formação continuada com conteúdos voltados às metas da escola e à melhoria do desempenho dos alunos, com apoio da equipe de supervisão e oficina pedagógica da DE.

5 - O horário do cumprimento das HTPCs, a ser organizado pelo Professor Coordenador, deverá assegurar que todos os professores do respectivo segmento de ensino participemnum único dia da semana, em reuniões de, no mínimo, duas horas consecutivas".

Os participantes dos eventos — professores de um mesmo segmento do ensino e professor coordenador, - são especificados pela legislação como também a assimetria das relações de lugares - ou posições hierárquicas - e os papéis - ou funções dos participantes (MATENCIO, 1999, KERBRAT-ORECCHIONI, 2006). O coordenador deve planejar e organizar as HTPCs, conforme o primeiro comunicado, "em sintonia com a equipe gestora", ou seja, com outros coordenadores e diretores da rede de ensino, o que envolve todas as ações detalhadas no quarto tópico do segundo comunicado, que se relacionam ao planejamento, organização e condução de HTPCs. Os professores ficam subordinados ao coordenador, pois é este que avalia "as demandas dos professores frente às metas e prioridades da escola". Também é ele que deve "organizar as ações de formação continuada".

Os documentos que regulamentam a HTPC contemplam como interlocutor apenas o professor coordenador. Este é referido várias vezes Olh@res, Guarulhos, v. 2, n. 2, p. 60-85. Dezembro, 2014. 
A formação continuada no local de trabalho do professor e a construção de uma comunidade de prática: possibilidades de agência social

no documento como o agente da HTPC, mesmo nas construções na voz passiva: "As Horas de Trabalho Pedagógico Coletivodeverão ser planejadas e organizadas pelo Professor Coordenador","O horário do cumprimento das HTPCs, a ser organizado pelo Professor Coordenador". O professor não é tomado como interlocutor - não há explicitações de suas funções na HTPC, somente o dever de comparecer à reunião e seguir decisões alheias, não sendo posicionado como agente, somente como objeto de ações de outros: "considerar as demandas dos professores frente às metas", "dividir entre os participantes as tarefas inerentes às reuniões", "com vistas a integrar o conjunto de professores do segmento, objeto da coordenação".

Essas construções relevam a apreciação valorativa do enunciador dos comunicados, no caso, a CENP sobre os professores. Essa apreciação é de que os docentes participantes são sujeitos passivos, sem funções relevantes na HTPC, quase um espectador, ou um "objeto" da coordenação. A relação de poder hegemônica e histórica entre órgãos oficiais reguladores da educação e o professor é reafirmada: este é colocado em uma posição subalterna, nunca como agente que possa organizar o evento, trazer questões e soluções para sua própria formação e para sua atuação profissional. O documento endossa o discurso hegemônico e atua como força centrípeta, reafirmando um papel subalterno ao professor, mesmo em um contexto privilegiado para sua ação em sua própria formação: seu local de trabalho.

Os documentos preveem uma rígida estrutura nos eventos, sempre tendo o professor coordenador como responsável pela sua realização, com pauta previamente elaborada, duração e horário fixos. Essa rigidez se reflete nas HTPCs semanais observadas, em sua condução pela coordenadora e na participação das professoras.

Contudo, a institucionalização do evento não impede que alguns aspectos sejam negociados na interação, como a assimetria das relações de lugares e papéis dos participantes. Até mesmo tempo e espaço da

Olh@res, Guarulhos, v. 2, n. 2, p. 60-85. Dezembro, 2014. 
HTPC são negociados e modificados, como no caso dos encontros quinzenais no contexto desta pesquisa: o grupo de professoras de $5^{\circ}$ ano de todo o município não participava da HTPC de sua escola, e sim se reunia em um mesmo local, em horário alternativo, durante 2 horas, para discutir uma pauta específica relacionada à exigência de avaliações externas desse ano de ensino. A pauta com tópico único dessas reuniões, diferentemente da pauta da HTPC na escola, não era preparada pela coordenadora, mas era negociada por todas as professoras, e preparada por uma dupla composta por professoras ou professora e coordenadora, duplas que se revezavam na realização dos eventos. Essa organização gera a possibilidade de as professoras se posicionarem como agentes sociais em sua própria formação, como veremos na seção a seguir.

\section{A (auto)formação continuada e agência social}

A organização dos eventos de HTPC quinzenal, com professoras de $5^{\circ}$ ano de toda a rede e coordenadoras das escolas, surgiu por uma iniciativa da Secretaria Municipal de Educação tendo em vista avaliações externas (SARESP e Prova Brasil) a que os alunos deste ano do ensino seriam submetidos ao final do ano letivo. As professoras atuantes no $5^{\circ}$ ano de toda a rede, quinzenalmente, não participavam da HTPC de sua escola e se reuniam para abordar questões, matrizes de referência e conteúdos relacionados a uma das avaliações externas.

Apesar de gerado por forças hegemônicas - as avaliações externas e a Secretaria Municipal de Educação - esse tipo de HTPC possibilitou, no contexto observado, subversões do que era recomendado em documentos oficiais e pela própria secretaria. Uma diferença importante entre este tipo de reunião e a semanal em cada unidade escolar com professores de $1^{\circ}$ a $5^{\circ}$ ano do EFI é a existência de um foco específico - a formação do professor tendo em vista avaliações externas a que seus alunos são submetidos. $\mathrm{O}$ foco restringe, de fato, as funções do 
A formação continuada no local de trabalho do professor e a construção de uma comunidade de prática: possibilidades de agência social

evento: questões de gestão escolar, muito recorrentes da reunião semanal na escola, não são abordadas.

Os encontros, exceto o primeiro, organizado diretamente por funcionárias da Secretaria de Educação, tinham uma pauta única. Também não havia ata, somente uma lista de presença, nem avisos da Secretaria ou outras atividades relativas à gestão. Com base na lista de temas produzida no primeiro encontro, por sugestão do grupo, uma dupla de professoras preparava o encontro. Geralmente, a dupla responsável por cada encontro era formada por uma professora e a coordenadora de sua escola ou por duas professoras de uma mesma escola.

Nas HTPCs entre professoras de $5^{\circ}$ ano, o objetivo comum do grupo e o rodízio entre coordenadoras e professoras para organizar os encontros e abordar os temas escolhidos pelo grupo são fatores que parecem favorecer a emergência de um espaço de agência das professoras em sua própria formação. $\mathrm{O}$ fato de não haver apenas uma pessoa, sempre a mesma, responsável pelo evento (a coordenadora da escola) e a concentração em uma única finalidade possibilitam a organização da interação de maneira distribuída e mais simétrica entre as participantes. Em contraste com estruturas interacionais em que as professoras têm pouco espaço para serem ouvidas sobre o que querem discutir (como cursos nas universidades, palestras ou mesmo em HTPC semanal na escola), eventos que levam em conta essa voz professoral inovam as formas de interação. Além disso, os saberes experienciais das professoras são valorizados por suas colegas e tomados como referência para a formação.

A relação mais simétrica entre as participantes das HTPCs quinzenais aparece na própria estrutura de participação das interações. Geralmente, os encontros são organizados com dinâmicas que simulam a sala de aula, e as professoras são colocadas para agir nesse tipo de encenação, realizando reflexões sobre os conteúdos, sobre a prática pedagógica e sobre a aprendizagem dos alunos antes ou após as

Olh@res, Guarulhos, v. 2, n. 2, p. 60-85. Dezembro, 2014. 
encenações. No exemplo a seguir, após as professoras apresentarem o tema do evento - o ensino de fração e porcentagem - logo passam a exemplificar atividades a serem realizadas com os alunos, que são encenadas com o grupo de professoras presentes. Não há uma descrição de como uma atividade poderia ser feita, e sim uma encenação de sala de aula, o que aproxima o desenvolvimento do evento a uma oficina, como vemos no excerto a seguir:

Excerto 1: Encenação de aula. Dinâmica para ensinar fração - "Bolo favorito da turma". [HTPC quinzenal, 01 de agosto de 2011, $4^{\circ}$ encontro observado. Priscila e Daniela em frente da sala, professoras sentadas em semicírculo]

\begin{tabular}{|l|l|}
\hline 1 & Pri: então depois dessa ideia nós vamos entrar numa dinâmica vocês podem fazer com \\
\hline 2 & as crianças algumas já conhe::cem é:: então posso começar? (...) que tipo de bolo vocês \\
\hline 3 & gostam? (...) eu quero assim umas ideias umas quatro ou cinco ideias \\
\hline 4 & Pri: chocola::te ((várias falam ao mesmo tempo)) \\
\hline 5 & Dani: ela gosta de recheado \\
\hline 6 & Prof: é recheado \\
\hline 7 & Pri: tá... rechea:::do, bolo de chocolate, cenoura... (...) \\
\hline 8 & Prof: bolinho de fubá \\
\hline 9 & Pri: então vamos lá agora vocês podem fazer isso com os alunos que dá muito certo \\
\hline 10 & agora quero que vocês só pode uma vez vou (...) só uma vez quantas nós estamos em? \\
\hline 11 & quantas ((conta)) dezessete comigo e com a Dani dezenove $(+)$ quem prefere bolo \\
\hline 12 & recheado? \\
\hline 13 & Dani: Pode levantar a mão bem alto... três \\
\hline 14 & Prof: tem que escolher um só? \\
\hline 15 & Dani: só UM \\
\hline
\end{tabular}

A interação é uma encenação de sala de aula para construir um modelo de aula que as professoras podem dar a suas turmas (linha 9). Há momentos em que Priscila retoma o turno para relembrar a finalidade da dinâmica ("então vamos lá", linha 9) e para direcionar o fazer das participantes. Na linha 13, Priscila solicita que levantem a mão "bem alto", de modo semelhante ao que os alunos fazem em sala de aula.

A encenação de uma aula, como modelo para o desenvolvimento de uma atividade que pode ser tomada como referência ou objeto de reflexão das professoras, caracteriza o evento como uma oficina, pois as participantes são colocadas a realizar o modelo sugerido. Vivenciar uma

Olh@res, Guarulhos, v. 2, n. 2, p. 60-85. Dezembro, 2014. 
A formação continuada no local de trabalho do professor e a construção de uma comunidade de prática: possibilidades de agência social

situação semelhante à vivida em sala de aula é uma estratégia de formação interessante para mobilizar os saberes experienciais (TARDIF, 2000) das professoras e elaborar novas maneiras de agir em sala de aula, como ocorre na continuação da interação:

Excerto 2: Continuação da dinâmica para ensinar fração "Bolo favorito da turma" (logo após professoras terem votado em sabores de bolo que preferem) [HTPC quinzenal, 01 de agosto de $2011.4^{\circ}$ encontro observado].

\begin{tabular}{|l|l|}
\hline 1 & Pri: certo gente vai fazendo com as crianças vamos ver se todo mundo votou... certinho \\
\hline 2 & Dani: agora vou pedir para que todas se levantem vamos fazer um círculo aqui \\
\hline 3 & ((professoras se levantam)) juntinho, juntinho... ((inaudível, muitas vozes, professoras se \\
\hline 4 & posicionam no centro da sala)) \\
\hline 5 & Pri: cenoura aqui ((vai desenhando um círculo no chão com barbante pelos sabores e \\
\hline 6 & cada professora que votou no sabor fica posicionada na parte correspondente)) como se \\
7 & fosse um compasso... \\
8 & Prof: oh que lega::I \\
9 & Pri: pode entrar no círculo, fubá ((risos)) \\
\hline 10 & Dani: aí pode entrar na roda... ((forma-se um gráfico em formato de pizza com as \\
\hline 11 & pessoas, os barbantes ficam no chão formando o gráfico)) \\
\hline 12 & Pri: podem sentar [palmas] \\
\hline
\end{tabular}

As professoras responsáveis pelo encontro propõem a encenação de uma atividade para construção de um gráfico do tipo pizza com o posicionamento dos alunos em pé e em grupos separados por barbantes. Daniela e Priscila agem como se estivessem em sala de aula com os alunos, indicando o início de uma etapa da atividade ("agora") e orientando o comportamento e a ação das participantes ("se levantem", "pode entrar no círculo"). Não há uma descrição de uma atividade didática, mas sua realização concreta, como acontece em oficinas.

A encenação parece compor o discurso profissional-didático, que parte da experiência das professoras. Conforme Tardif (2000), é o saber experiencial que orienta principalmente o fazer do professor. Nesse caso, outros saberes, como o disciplinar e o curricular, compõem a sugestão de atividade, mas o foco principal do evento é a exemplificação do como fazer em sala de aula, como ensinar com base em experiências didáticas

Olh@res, Guarulhos, v. 2, n. 2, p. 60-85. Dezembro, 2014. 
anteriores das professoras.

Apesar de enfocarem mais o como fazer, as professoras não só o encenam, mas refletem sobre as sugestões de atividades, sobre possíveis metodologias, mobilizam os conceitos a serem ensinados e aprendidos. Após a dinâmica, as duas professoras que prepararam o encontro abordam a metodologia de ensino da fração em sala de aula:

Excerto 3: Reflexão após Dinâmica para ensinar fração "Bolo favorito da turma" [HTPC quinzenal, 01 de agosto de 2011. $4^{\circ}$ encontro observado. Priscila e Daniela em frente da sala, professoras sentadas em semicírculo]

\begin{tabular}{|l|l|}
\hline 1 & Dani: nós não precisamos ainda assim conceituar dar no caderno pra ele fazer adição de \\
\hline 2 & fração mas se a gente perguntar agora aqui pra eles "olha quantos pedaços foi dividido \\
\hline 3 & aqui? Se somasse tudo, não daria dezessete novamente? É o nosso inteiro" mas eu \\
\hline 4 & Preciso colocar pra ele lá no caderninho que tem que ser isso mais isso para dar adição \\
\hline 5 & de fração? Não nesse momento mas só através da oralidade a gente já está dando o \\
\hline 6 & conceito... \\
\hline 7 & Pri: também gente levar a criança a perceber neste momento que o todo aqui é \\
\hline 8 & dezessete não é cem... né? \\
\hline 9 & Dani: que nosso cem por cento ((outras falam)) cem por cento é dezessete quer dizer \\
\hline 10 & depois que ele aprendeu toda aquela parte aprendeu o que é o cem por cento a gente já \\
\hline 11 & passa para um todo diferente daquele cem o nosso todo não é mais o CEM o nosso todo \\
\hline 12 & agora é dezessete em cima do dezessete nós fracionamos \\
\hline 13 & Prof Clarice: você falou pra não cobrar ahn.: mas eu gostaria de saber... \\
\hline 14 & Dani: o que será cobrado? \\
\hline 15 & Clarice: é exatamente... no sexto ano/ porque se eles cobrarem (...) eu costumo expor as \\
\hline 16 & duas partes para achar o denominador comum... (...) simplificação vai ou não? \\
\hline 17 & Dani: não... o que vai ser cobrado na avaliação é isso \\
\hline 18 & Pri: depois vem a quinta série a sexta série né ... \\
\hline 19 & Dani: lógico no quarto bimestre a gente vai... aprofundar um pouco mais mas nesse \\
\hline 20 & momento o terceiro bimestre o que cobrar... \\
\hline 21 & Clarice: ó mas eu vou falar uma coisa pra você (...) a gente tem visto...se nós se a nossa \\
\hline 22 & turma permitir avançar a turma avançar a gente tem que fazer sim porque eles vão pra \\
\hline 23 & quinta série as classes superlotadas e os professores acham que eles têm obrigação de \\
\hline 24 & saber TU.:.:DO \\
\hline 25 & Profs: é mesmo, é sim \\
\hline
\end{tabular}

O enfoque é o saber-fazer do professor em sala de aula, passando também por uma explicação desse fazer, que demanda reflexão sobre a prática. As professoras participantes intervêm, colocam questões para debate relacionadas sobre os conteúdos que serão cobrados na avaliação. A organização do evento como oficina também possibilita a construção

Olh@res, Guarulhos, v. 2, n. 2, p.60-85. Dezembro, 2014. 
A formação continuada no local de trabalho do professor e a construção de uma comunidade de prática: possibilidades de agência social

de relações mais simétricas, em que todas podem participar, tomar o turno, sem controle e distribuição de turnos por uma única pessoa. Clarice compartilha como costuma fazer em sua sala de aula (linhas 15 e 16), colocando sua experiência como professora e seus conhecimentos sobre a situação do Ensino Fundamental II (linhas 22 e 23). Clarice utiliza a modalidade deôntica ("a gente tem que fazer sim”) e enuncia como alguém que sabe o que será cobrado dos alunos nas fases subsequentes da escolarização (linhas 23 e 24), intervenção que é permitida e acolhida pelas demais devido à própria configuração dos encontros: uma oficina, em que profissionais, numa relação simétrica, demonstram e debatem possibilidades de trabalho pedagógico.

A organização dos encontros como oficinas, com realização prática de atividades didáticas e debates sobre estas, é sustentada por saberes experienciais das professoras, direcionada para suas próprias demandas de formação e relacionada com questões profissionais por elas selecionadas como relevantes. A HTPC voltada exclusivamente para a formação do professor, sem discussão de questões de gestão escolar, e organizadas e coordenadas pelas próprias professoras, entre iguais, apresenta participação ativa das professoras, que se colocam como debatedoras, intervêm, tomam o turno da dupla que realiza o encontro, contestam, relacionam o tema a outros conhecimentos profissionais etc.

O excerto abaixo, que se refere a outro evento deste tipo, ocorre após uma longa fala de Marina sobre revisão e reescrita de textos em sala de aula, tema selecionado para a HTPC em questão. Quando passa a abordar o tópico relativo aos modos de fazer, as professoras iniciam o debate:

Excerto 4: Estrutura de participação em oficina: compartilhando como fazer [HTPC quinzenal, 05 de setembro de 2011, Marina e Tânia em frente da sala, professoras em semicírculo]

Olh@res, Guarulhos, v. 2, n. 2, p. 60-85. Dezembro, 2014. 


\begin{tabular}{|l|l|}
\hline 1 & Eliane: uma questão também pra gente pensar um pouco dessa:: revisão textual que ela \\
\hline 2 & é tão ou mais importante que a produção né que às vezes a gente escreve escreve \\
\hline 3 & escreve e não para nunca pra revisar lógico que eu to falando bem uma coisa bem assim \\
\hline 4 & né... mas a revisão ela é tão importante ou até mais que a produção e tirar o foco muito \\
\hline 5 & do professor deixar também a revisão entre alunos o professor vai ser o orientador o \\
\hline 6 & mediador disso mas ela vai em determinado momento deixar essa revisão nas duplas \\
\hline 7 & Marina: é:: troca NE \\
\hline 8 & Cristiane: eu coloco em duplas com o dicionário do lado \\
\hline 9 & Marina: olha que sugestão boa \\
\hline 10 & Carolina: então eu fazia uma lista de palavras e pedia pra eles fizessem revisão \\
\hline 11 & ortográfica aí pedia que colocassem em ordem alfabética e "agora vamos utilizar o \\
\hline 12 & dicionário?" às vezes tinha palavra que lógico não tinha nada a ver e "não gente essa \\
\hline 13 & palavra significa tal coisa assim procura se está correto assim do jeito que está escrito" \\
\hline 14 & nossa em dupla em trio e ia embora... \\
\hline 15 & Marina: então eu já cheguei a falar assim [Carolina: foi muito bom] nossa hoje não tem \\
\hline 16 & nada parece que não dei nada mas é porque é uma atividade que pega bastante tempo é \\
\hline 17 & uma atividade/ mas você vê que tem resultado \\
\hline 18 & Fernanda: a lousa digital é um recurso interessante por exemplo a gente pode escanear o \\
\hline 19 & texto de um aluno jogar lá e usar cada cor pra corrigir uma coisa e eles vão vendo o erro e \\
\hline 20 & vão ajudando você \\
\hline 21 & Marina:a gente tá fazendo isso eu to digitalizando e algumas professoras elas tão dando \\
\hline 22 & assim bem diversificado é coletivo é::: escolher uma porque pegar de todo mundo às \\
\hline 23 & vezes não dá então tem várias maneiras \\
\hline 24 & Gabriela: mesmo se não escanear dá pra digitar o próprio texto com os mesmos erros e ir \\
\hline 25 & mexendo... \\
\hline
\end{tabular}

$\mathrm{Na}$ troca de turnos, as professoras enunciam a todo o momento suas apreciações valorativas sobre como trabalhar escrita e reescrita, construindo posicionamentos de profissionais com experiências a serem compartilhadas ("é tão ou mais importante", "olha que sugestão boa", "foi muito bom", "interessante"). Os adjetivos com função de modalizadores avaliativos indicam apreciações valorativas positivas das professoras sobre o objeto de discurso e sobre si mesmas e suas colegas como profissionais. No debate, a troca de turnos é constante e os interlocutores têm o mesmo lugar interativo. Não há um participante que distribui os turnos ou os controla, não há marcadores de alguma relação hierárquica. Os participantes tomam o turno consecutivamente, um respondendo ao outro. A intervenção de Eliane aborda maneiras de se realizar a revisão e a reescrita de textos, tema escolhido para o encontro deste dia. Eliane avalia como "mais importante" a reescrita do que a produção de texto e

Olh@res, Guarulhos, v. 2, n. 2, p. 60-85. Dezembro, 2014. 
A formação continuada no local de trabalho do professor e a construção de uma comunidade de prática: possibilidades de agência social

faz a sugestão de realizar a revisão em duplas de alunos (linha 6 -7). Essa sugestão é retomada por Cristiane (linha 8), que complementa a sugestão com sua maneira de fazer: com o uso do dicionário. Marina, uma das responsáveis pelo evento, avalia a contribuição (linha 9), mas não centraliza nem distribui os turnos; várias professoras fazem breves relatos de maneiras de fazer a revisão textual em sala de aula, compartilhando experiências e avaliando suas próprias sugestões e as sugestões das outras professoras. Carolina avalia sua própria prática pedagógica ("foi muito bom"). Fernanda avalia o uso da lousa digital ("recurso interessante").

$\mathrm{Na}$ maioria das intervenções, as professoras se utilizam do pronome de autorreferênciaeu, colocando-se como agentes de suas atividades profissionais de sala de aula ("eu coloco em duplas", "eu fazia uma lista", "eu já cheguei a falar", "eu to digitalizando"). As professoras se posicionam como sujeitos ativos com motivações para atingir um objetivo (ARCHER, 2000), no caso, o ensino-aprendizagem da reescrita, exercendo agência em sua formação. Há uma busca por construção coletiva de conhecimento para agirem em seu contexto profissional, o que pode proporcionar um posicionamento das professoras como agentes de letramento que, conforme Kleiman (2006), é aquele que atua de maneira direcionada para as ações coletivas, buscando a co-construção do conhecimento. Dentro dessa concepção, "todos os participantes da interação são potencialmente mediadores, ao mobilizarem recursos de outros eventos, outras situações, outras práticas sociais" (KLEIMAN, 2006, p. 81). A construção de uma comunidade de prática (LAVE, WENGER, 1991), ou seja, de um grupo de pessoas unidas em torno de um mesmo interesse, que trabalham juntas na resolução de um problema ou no aprendizado de um tema, favorece o posicionamento como agentes pelas professoras e dá a todas a possibilidade de serem potencialmente mediadoras em sua própria formação.

$\mathrm{O}$ conceito de agência social se refere a atividades reais de indivíduos atuando no mundo social, através da ação coletiva (ARCHER,

Olh@res, Guarulhos, v. 2, n. 2, p. 60-85. Dezembro, 2014. 
2000). De acordo com Archer (2000), a agência social implica se engajar e promover ações coletivas. Os agentes sociais são sujeitos ativos, que agem estrategicamente, tendo em vista objetivos específicos de um grupo. Eles articulam os interesses de membros do grupo, os organizam para a ação conjunta, para exercitar influência como coletividade.

Diferentemente da agência humana, agir socialmente pressupõe reflexão e estratégia, mesmo que também influenciadas pela subjetividade dos sujeitos e pelos discursos disponíveis num dado contexto. Zavala (2011) define agência social como capacidade socioculturalmente mediada que os indivíduos escolhem para agir sob os efeitos das forças ideológicas que construíram sua subjetividade. Mesmo que perpassados pela subjetividade e por ideologias, que influenciam os atos escolhidos, um agente social é sempre ativo, nunca um mero receptor de ações alheias (ARCHER, 2000; KLEIMAN, 2006; ZAVALA，2011; KLEIMAN, VIANNA, DE GRANDE, no prelo). Ele também nunca é solitário, pois precisa da ação coletiva para atingir os objetivos traçados.

Diferentemente do esperado pelos documentos que regulamentam a HTPC, que posicionam professores como objetos da ação de coordenadores, as professoras se posicionam como agentes sociais, organizam sua própria formação no local de trabalho, selecionam seus temas de interesse e respondem a suas próprias demandas de formação. Ao compor uma comunidade de práticas provisória - grupo de professoras de $5^{\circ}$ ano de toda a rede municipal de ensino - as professoras constroem um coletivo para se autofortalecerem como grupo e se autoformarem como profissionais da educação, que podem organizar sua própria formação em serviço.

\section{Considerações finais}

Os eventos de formação analisados são gerados pela necessidade de resolução de problemas emergentes da prática de sala de aula, que têm Olh@res, Guarulhos, v. 2, n. 2, p. 60-85. Dezembro, 2014. 
A formação continuada no local de trabalho do professor e a construção de uma comunidade de prática: possibilidades de agência social

como meta aprender a ensinar. O tratamento dos tópicos mostra modos de produção de conhecimentos orientados pela experiência numa relação simétrica entre iguais.

Tendo em vista a resolução de um problema ou demanda educacional, as professoras criam uma comunidade que prioriza trocas de experiências e saberes e, com essa organização, formador e formando se configuram como papéis dinâmicos, assumidos por diferentes participantes (NÓVOA, s/d). A prática de compartilhar experiências do trabalho e discuti-las se constituiu como uma prática de letramento formativa na medida em que se constroem na interação novos conhecimentos sobre a prática pedagógica, sobre o objeto de ensino, sobre o próprio trabalho do professor, com base em saberes experienciais e disciplinares anteriores das participantes. Conhecer essas práticas de letramento formativas no local de trabalho do professor e como os próprios docentes asdefinemcomo formativas pode servir para formadores de professores repensarem seu próprio fazer como também direcionar políticas públicas relacionadas aos docentes.

A delimitação de HTPC como momentos de formação tendo em vista às avaliações externas, um objetivo bastante preciso, e a organização com alternância de quem assume o papel de formadora, parecem contribuir para uma interação mais colaborativa e a formação de um grupo coeso, com interesses em comum. A natureza dos saberes mobilizados, aqueles mais relacionados à prática, às experiências docentes das participantes, também favorecem a participação, pois todas têm experiências a compartilhar. É preciso destacar, contudo, que saberes técnicos e especializados são também mobilizados, mas sempre em função do saber-fazer. O enfoque das participantes e suas demandas incidem mesmo nos modos de fazer em sala de aula, presentes em todas as reuniões desse tipo, o que não exclui o diálogo com saberes disciplinares e curriculares.

A construção de um coletivo para se identificar - docentes em

Olh@res, Guarulhos, v. 2, n. 2, p. 60-85. Dezembro, 2014. 
busca de respostas a necessidades imediatas de ensino-aprendizagem de seus alunos - favorece a formação das professoras em seu local de trabalho. Esse reposicionamento de uma posição subalterna dada pelos documentos que regulamentam a HTPC para uma posição de autorização em relação a seu dizer e seu fazer parece se sustentar na construção dessa voz coletiva.

O que parece indicar a análise é que a delimitação de um interesse comum e a criação de um coletivo que se autofortalece favorecem uma interação simétrica e uma formação em que as próprias professoras exercem agência, direcionando-a para suas demandas. Essa simetria e a possibilidade de agência engajam as professoras em sua própria formação, tornando-a mais efetiva para os interesses dessas profissionais. 
A formação continuada no local de trabalho do professor e a construção de uma comunidade de prática: possibilidades de agência social

Referências Bibliográficas:

ARCHER, Margaret S. Being Human: The Problem of Agency. Cambridge: Cambridge University Press, 2000.

BAKHTIN, M./ VOLOCHINOV. Marxismo e Filosofia da Linguagem. Ed. 7. São Paulo: Hucitec, 1995.

BAKHTIN, M. O discurso no romance. In: Questões de Literatura e Estética. São Paulo: Hucitec, 1988.

Estética da Criação verbal. Tradução Paulo Bezerra 4a.ed. Martins Fontes, 2003.

FABRÍCIO, B. F. Lingüística Aplicada como espaço de desaprendizagem: redescrições em curso. In: MOITA-LOPES, L. P. (org.) Por uma Linguística Aplicada Indisciplinar. São Paulo: Parábola Editorial, 2006.

GOFFMAN, E. Ritual de Interação: ensaios sobre o comportamento face a face. São Paulo: Vozes, 2011.

KERBRAT-ORECCHIONI, C. Análise da conversação: princípios e métodos. São Paulo: Parábola, 2006.

KLEIMAN, A. Modelos de letramento e as práticas de alfabetização na escola. Os significados do letramento. Campinas, SP: Mercado de Letras, 1995.

. A construção de identidade em sala de aula: um enfoque interacional. In:

Signorini, I, (org.) Língua(gem) e identidade. Campinas, SP: Mercado de Letras, 1998.

Olh@res, Guarulhos, v. 2, n. 2, p. 60-85. Dezembro, 2014. 
. As metáforas conceituais na educação lingüística do professor: índices da transformação de representações e saberes na interação. In: Kleiman, Angela B.; Matencio, Maria de Lourdes M.. (Org.). Letramento e formação do professor. Práticas discursivas, representações e construção do saber. 1ed. Campinas: Mercado de Letras, 2005, p. 203-228.

. Professores e agentes de letramento: identidade e posicionamento social. RevistaFilologia e Linguística Portuguesa, São Paulo, n. 8, 2006.

Agenda de pesquisa e ação em Linguística Aplicada: problematizações. In:

MOITA LOPES, L. P. Linguística Aplicada na modernidade recente: festschriftpara Antonieta Celani. São Paulo: Parábola, 2013.

KLEIMAN, A., VIANNA, C. A. D., DE GRANDE, P. B."Sem querer ir contra pessoas tão ilustres...": construção e negociação identitárias em situações de comunicação intercultural. Revista Scripta. No prelo.

LAVE, J.; WENGER, E.Situated Learning: Legitimate Peripheral Participation. Cambridge, 1991.

MATENCIO, M.L.M. Estudo de Língua falada e aula de língua materna: uma abordagem processual da interação professor/alunos. Tese (Doutorado), Linguística Aplicada, Instituto de Estudos da Linguagem, Universidade Estadual de Campinas, Campinas, 1999.

. Estudos do letramento e formação de professores: retomadas, deslocamentos e impactos. Caleidoscópio. V.7, n.1, p. 5-10, jan/abr 2009.

NÓVOA, A. Formação de professores e profissão docente. Sem data. Disponível em $<$ http://repositorio.ul.pt/bitstream/10451/4758/1/FPPD_A_Novoa.pdf $>$. Acesso em 08/01/2013.

Olh@res, Guarulhos, v. 2, n. 2, p. 60-85. Dezembro, 2014. 
A formação continuada no local de trabalho do professor e a construção de uma comunidade de prática: possibilidades de agência social

OLIVEIRA, N. A. R.A HTPC como espaço de formação: uma possibilidade. Dissertação (mestrado), Pontifícia Universidade Católica de São Paulo, 2006.

SANTOS, C.B., ORGE L.M. Letramento do alfabetizador no local de trabalho. In: VÓVIO, C.L.; SITO, L.S.; DE GRANDE, P.B. LetramentoS: rupturas, deslocamentos e repercussões de pesquisas em Linguística Aplicada. Campinas: Mercado de Letras, 2010.

SANTOS, C.B. ...Tá sempre no assunto: a construção da noção de coerência textual pelo professor em formação. In: KLEIMAN, A. e MATENCIO, M.L.M. Letramento e formação do professor. Campinas: Mercado de Letras, 2005.

SÃO PAULO. Portaria da Coordenadoria de Estudos e Normas Pedagógicas n $1 / 96$, L.C. $n^{\circ}$ 836/97.

SILVA, J.Q.G. e MATENCIO, M.L.M. Referência pessoal e jogo interlocutivo: efeitos identitários. In: KLEIMAN, A. e MATENCIO, M.L.M. Letramento e formação do professor. Campinas: Mercado de Letras, 2005.

SOUZA, Aparecida Neri. Sou professor, sim senhor! Representações do trabalho docente. Campinas: Editora Papirus, 1996.

TARDIF, M. Saberes docentes e formação profissional. 3 ed.Petrópolis, RJ: Vozes, 2003.

- Saberes profissionais dos professores e conhecimentos universitários.

RevistaBrasileira de Educação. no. 13, Jan/Fev/Mar/Abr 2000.

ZAVALA, V. La escritura académica y la agencia de lossujetos, CuadernosComillas, I, 52-66, 2011.

Olh@res, Guarulhos, v. 2, n. 2, p. 60-85. Dezembro, 2014. 